not necessarily follow, as it might be said that getting up in the morning is part of a physiological cycle. I do not wish to claim any particular credit for any contribution I hsve made to our knowledge of this subject, but I do wish to point out that it is not by any means absolutely selferident what is the true cause of the albuminuria, simply hecause we know that it has a relation to the position of the body. In truth, no inconsiderable number of possible causes have to be considered; for instance, among others, and omitting the question of food, there are exercise, passive congestion, pressure on vessels induced by an alteration in the position of viscera on standing up, and an increased vascular tension supposed to be physiological at puberty, all of which theories have been advanced by eminent physicians after the study of cases and in full possession of a knowledge of the facts.

I am, Sirs, yours faithfully,

Grays, Essex, April 18th, 1888. ALEXANDER W. STIRLING.

Sras,-Will you allow me a word on what Dr. Pavy designates as "Cyclic Albuminuria"? Many (thirty) years «go I treated a patient for scarlatinal nephritis. He thoroughly recovered; but, as I had great interest in the case, I used to examine for albumen for many (nine or ten) months after its thorough disappearance. Occasionally I used to find traces in the urine which was passed at midday when I had discovered none the first thing in the morning. On inquiry I found that my patient used to take sharp morning spells at rowing. I at once arrived at the conclusion that its occasional presence was due to the mechanical pressure of the abdominal muscles causing a "back thrust" on the kidneys and their veins. I was in the habit of calling it "mechanical albuminuria," as that seemed to me its only exciting cause. The patient is still living, and quite healthy. I am, Sirs, yours faithfully,

Surbiton, April 17th, 1888. HENRT GODRICH.

\section{AN ANSWER TO DR. MAX NITZE'S PROTEST.}

To the Editors of THE LANCET.

SIRS,-In a very able, and to me deeply interesting, communication in your issue of last week, Dr. Nitze of Berlin draws renewed attention to his valuable method of diagnosing obscure vesical disease by means of electric illumination. The worth of the article is unfortunately detracted firom by the introduction of an acrimonious dispute between Dr. Nitze and his instrument maker, Leiter of Vienna. To my surprise, he has transferred the squabble from the German press to English columns, and has endeavoured in the article I quote to make me participate by referring to $m e$ in the following terms: "I must strongly contradict Mr. Fenwick's statements concerning the share which he has attributed to the Vienna instrument maker in the construction of the instrument. ...... I protest most emphatically against every connexion of Liter's name with my instrument." No effort of Dr. Nitzy's now can erase from the literature whence I derived my "statements" the coupling of his name with Leiter in the history of the Nitze-Leiter Cystoscope. This disclaimer should have appeared in 1879 , before the innovation was thus denominated in every European language (compare THe LaNCET, 1879, 1880). Moreover, $i$ tappears to me, an impartial reader, as savouring of a recantation. Dr. Nitze's printed eulogy of Mr. Leiter in 1879 accords but ill with the expression of antagonism now. I quoted from Dr. Nitze's speech, but for this quotation I am censured. My words were these: "In 1877 Dr. Nitze grappled with the problem (of electric endoscopy), and Leiter, the woll-known instrument maker (f Fienna, was entrusted with its solution. After ten months of expensive and indefatigable labour, Ltiter constructed an electric endoscope bv means of which the bladder could be effectively examined." Dr. Nitze's words ran as follows: "Before I came to Vienna the instruments were imperfectand unreliable in many respecta, and in their external appearance and shape there was $\mathrm{mu} \cdot \mathrm{h}$ to be desired. The real practical completion by the most important structural changes is due to the merit of Mr. Leiter, which cannot be estimater highly enough. For ten months he has thrown his whole strength and energy into the work, and shrank from no financial sacrifice to render the instrument as perfect and as practical as possible. ...... Mr. Leiter will demonstrate the instruments, and he is all the more competent to do so

as a part of the construction is evolved by himself, and is therefore in the hight st sense his intellectual property."

Fig. 1.

The reason why I thus quoted from

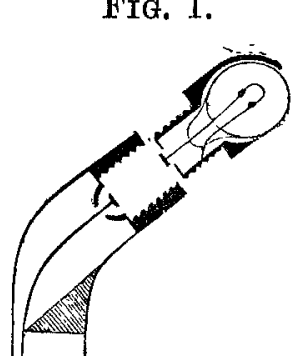

Dr. Nitze was an earnest wish to lay a valuable innovation before the profession without taking sides in a quarrel the rights of which I did not know, and to the issue of which I was supremely indifferent. Dr. Nitze introduced the method, and to him belongs the honour: what matters it whose instrument we use as long as it is the best and the most practical ?

This brings us to the second and minor point. Dr. Nitze "protests most emphatically against the (my) incorrect explanation of the construction of his (incandescent lamp) cystoscope." This is severe language for the expression of an individual opinion! The question very properly arose at the Medical Society "which of the two incandescent lamp cystoscopes-the Nitze or the Leiter pattern - was the better?". I promptly answered : "In my experience, the Leiter pattern is the more practical, for its lamp is less expensive and less troublesome to repair." Figs. $1 \&$ * The beak of the Nitze represent the beaks of the Nitze and the cystoscope.

Leiter cystoscopes. In Fig. 1 the carbon filament is cemented in the tip; in Fig. 2 it is loose and get-at-able. Given a broken lamp, which is the easier to repair? Fig. 1 shows that the entire tip in the Nitze pattern must be unscrewed and sent to the instrument maker (at Berlin) for renewal. Whilst in Leiter's cystoscope,

\section{FIG. 2.}
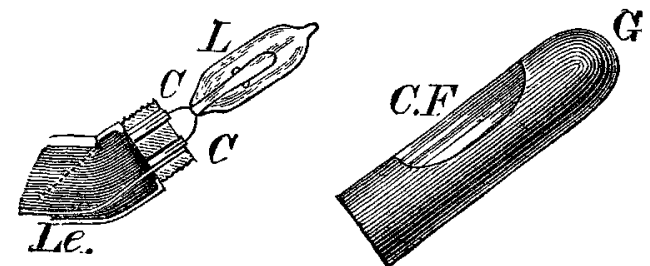

A, The lamp; B, the lamp adjusted; $\mathrm{c}$, the silver hood for the lamp (in Leiter's cystoscope).

if the lamp burns through, the bood has only to be unscrewed, the lamp pulled out, another slipped in, and the examination continues, after only a minute's interruption. How is it possible that Dr. Nitze can write such advice as this: "My instrument is superior to that made by Leiter, because of its greater simplicity in construction, which allows the lamp to be easily replaced if necessary." I do not complain of this ungracious return for my advocacy of Dr. Nitze's claims in every lecture and demonstration I have given upon the subject. The book I have written upon Electric Endoscopy, issuing from the press this week, contains evidence (for those who care to pursue the subject further) of strict impartiality, and of an admiration for Dr. Nitze, which has only just received so sudden a rebuff. I am, Sirs, yours faithfully,

April 23rd, 1888

E. HURRY FENWICK, F.R.C.S.

\section{MEDICAL MEN AS JURYMEN.}

To the Editors of THe LANCET:

SrRs,-On March 27th I received from the constable of one of the coroners of Middlesex a summons to serve on an inquest to be held on the $29 \mathrm{th}$. Thereupon, I wrote to the coroner (Dr. Dauford Thomas) stating that I had been in practice for thirty years and had not hitherto been summoned, and asking whether there had been any recent alteration in the law by which I had become liable to serve as a juryman. I received the following reply :-

$$
\text { "Coroner's Office, 68, St. Mary's Terrace, }
$$

'Paddington, W., March'28th, 1888.

"Drar SiR,-The coroner desires me to acknowledge the receipt of your letter of the $27 \mathrm{th}$ inst., and to inform you that these is no alteration in the law, with the exception that the fine for non-attendance has been increased from $40 s$. to $£ 5$. All mole persons, being British subjects of the 